\title{
Отношение логического следования в трактатах Северина Боэция ${ }^{1}$
}

\author{
Л. Г. Тоноян
}

\begin{abstract}
Definition of logic following in the doctrine of Boethius is considered in this article. The author investigates not available in Russian language treatises of Boethius «De hypotheticis syllogismis», «In Ciceronis Topica» etc. Following problems are solved in research: a parity of sillogistics of Aristotle and stoics, a parity of categorical and conditional judgements, definition of logic following at Boethius, the reason of occurrence of «wrong moduses» in the doctrine of Boethius.

Keywords: logical doctrine of Boetsius's, relation of logic, hypothetical syllogisms, «wrong moduses» of hypothetical syllogisms
\end{abstract}

Боэций (480-525) - одна из ключевых фигур в истории логики. Конгениальный переводчик на латынь «Органона» Аристотеля, он сумел передать логику античного греческого мира средневековому латинскому Западу, где стал считаться вторым после Аристотеля авторитетом в логике. Но в Новое время Боэцию стали отводить лишь роль комментатора трактатов Аристотеля. Однако в его логических трактатах мы встречаем положения, не имеющие соответствия в трактатах Аристотеля. Так, например, при рассмотрении гипотетических силлогизмов у Боэция мы сталкиваемся с «неправильными» модусами, т.е. с модусами, в которых, с нашей точки зрения, нарушено правило логического следования. В статье мы постараемся дать ответ на вопрос, как Боэций понимал отношение логического следования, и попробуем объяснить причину возникновения «неправильных» модусов, а также некоторых других нововведений Боэция.

\footnotetext{
${ }^{1}$ Исследование поддержано РГНФ, грант №11-03-00170а.
} 


\section{1 Античные концепции логического следования}

Одной из главных задач логики является универсальное определение логического следования, а одной из проблем истории логики остается вопрос о соотношении силлогистики Аристотеля и логической системы стоиков. Ведь именно стоикам ставят в заслугу открытие логики высказываний и соответствующую ей формулировку логического следования. Но так было не всегда. Формирование математической логики, вновь возникший интерес к логическому учению стоиков, проявленный в начале XX века, в корне изменили традиционные представления и привели к новым попыткам реконструкции стоического учения. В результате этих исследований возобладало мнение о принципиальном различии логических учений стоиков и перипатетиков. Так, считается, что в основе аристотелевской силлогистики лежит связь терминов, а в основе стоической логики - связь предложений. Прояснению этого вопроса, а также и некоторых других поможет, по всей видимости, обращение к логическим трактатам Боэция, содержание которых еще не нашло подробного анализа в наших историко-логических исследованиях. Трактаты написаны римским логиком 6 в. н.э., хорошо знакомым, как с силлогистикой Аристотеля, так и с не дошедшими до нас работами стоиков и перипатетиков.

Какие источники позволяют говорить о логике стоиков как самостоятельной системе? Несмотря на то что логика составляет одну из трех основных частей философии стоиков, фрагментов этой части учения насчитывается менее всего. Сочинения основателей Стои (Зенон, Хризипп) были утрачены, а поздние стоики логикой специально не занимались. В качестве источников используются фрагменты из произведений Секста Эмпирика, Диогена Лаэртского, ссылки Цицерона, Галена и некоторых других античных ученых. Собственно как о логике говорится только лишь о Хризиппе, при этом считается, что он детально разработал логическое учение Стои. Что же тогда было сделано Хризиппом в области формальной логики (а не гносеологии) по сравнению с Аристотелем? Прежде всего, отметим, что ни один из исследователей не отрицает влияния на стоиков аристотелевской силлогистики и модальной логики мегариков (Диодора Кроноса и Филона).

Изложим вкратце то, что известно о логике Хризиппа из тек- 
стов Секста Эмпирика и Диогена Лаэртского. Если силлогистика Аристотеля построена на родовидовых отношениях между терминами, то стоиков интересует причинная, условная связь между телесными сущностями и явлениями, поэтому в основу рассуждений они кладут не категорические (А есть В), а условные предложения (если первое, то второе). Условные высказывания составляют у стоиков один из трех видов сложных высказываний. Двумя другими Хризипп считает конъюнкцию: nервое и второе, и дизъюнкцию: первое либо второе. Истинность сложных высказываний может быть установлена либо эмпирически - через проверку истинности каждого простого высказывания, либо логически - путем формальной совместимости простых высказываний [1, с. 172]. Наибольший интерес представляет собой формальная (аналитическая) истинность условных высказываний: истинный вывод в них аналитически следует из истинной посылки. Такое высказывание стоики называли «знаком» (греч. сэмейон) [1, с. 197, 203]. Поскольку человеку свойственна последовательность мыслей, то знак состоит для него в следующем: «если это, то это». Только «знаки», согласно стоикам, способны выражать причинную связь. Поскольку исследование именно причинной связи ставится в заслугу стоикам, мы более подробно осветим трактовку ими условной связи. Другие виды связи - конъюнкция и дизъюнкция - выводятся из условного высказывания и разъясняют его. Так, при рассмотрении конъюнкции Хризипп выделяет отрицание конъюнкции, и указывает, что предложение «не вместе первое и не-второе» тождественно предложению «если первое, то второе». Дизъюнкция «или первое, или второе» понимается только в смысле строгого, контрадикторного разделения, и истинна только когда одно из простых суждений истинно. В форме «либо не первое, либо второе» дизъюнкция тождественна условному предложению «если первое, то второе». Иначе говоря, сводимость конъюнкции и дизъюнкции к импликации позволяет считать их видами одного гипотетического высказывания, в котором из наличия или отсутствия первого можно сделать вывод о наличии или отсутствии второго. Таким образом, возникает гипотетический силлогизм, который стоики считали главным инструментом познания. Основой логической системы стоиков считают выделен- 
ные Хризиппом пять не нуждающихся в доказательстве видов гипотетического силлогизма. Они неоднократно встречаются в источниках, например, во «Введении в логику» Галена [2], у Секста Эмпирика [1, т. 1, с. 193-194, т. 2, с. 292-293] и др.

1. Если первое, то второе; первое, следовательно, второе.

2. Если первое, то второе; не второе, следовательно, не первое.

3. Не вместе первое и второе; первое, следовательно, не втоpoe.

4. Либо первое, либо второе; первое, следовательно, не втоpoe.

5. Либо первое, либо второе; не второе, следовательно, первое.

Теперь обратимся к исследованиям, проведенным в XX веке. Проблеме логического следования в учении стоиков посвящена статья немецкого исследователя Юргена Мау «Стоическая логика. Ее место по отношению к аристотелевской силлогистике и современному исчислению высказываний» [3]. Ю. Мау, проведя обзор основных исследовательских работ XX века по логике стоиков (Поленца, Мейтса, Лукасевича, Бохеньского и др.), указывает, что в результате этих исследований закрепилась точка зрения, согласно которой принципиальное значение имеет тот факт, что Аристотель строил свою систему на связи терминов, а Хризипп исследовал связь между целыми высказываниями. И при этом Бохеньский полагает, что логические исследования проходили в рамках одной школы, считая, что в дошедших до нас источниках под «старшими» перипатетиками подразумеваются Теофраст и Эвдем, а под «младшими» - стоики с Хризиппом во главе. Форма категорического суждения $A$ ecmъ $B$ у Теофраста эквивалентна форме импликации если первое, то второе у Хризиппа.

Ю. Мау указывает, что Аристотель использует в силлогистике метод сведения к абсурду, который является специальным видом гипотетического доказательства. В «Первой Аналитике» [4] Аристотель пишет, что доказательства такого вида он хотел бы 
изложить систематически в другом месте. Александр Афродизийский в комментарии к данному отрывку добавляет, что Теофраст взял на себя выполнение этой намеченной учителем задачи и установил систему гипотетических выводов, которая в своем ядре уже содержала упомянутые аксиомы Хризиппа. Таким образом, стоическая логика выросла из логических исследований как мегариков, так и перипатетиков. Вплоть до второй половины I в. н.э. не могло идти даже речи о противоположности между аристотелевской и стоической логикой. Судя по всем источникам, это было одно направление ученых, считает Ю.Мау. Положение изменилось после опубликования Андроником Родосским в 30-х гг. I в. сочинений Аристотеля, когда стали широко использоваться для обучения логике логические методы, разработанные самим Аристотелем. Из греческих источников особый интерес, по мнению Ю.Мау, представляет сочинение эпикурейца Филодема ( вании знаков»). Папирус с этим сочинением случайно сохранился в пепле извергшегося в 79 г. н.э. Везувия. Здесь излагается спор между самим эпикурейцем Филодемом и стоиком Дионисием Киренским о том, как понимать условную, или причинную связь. Речь идет о том, может ли и как должно доказываться что-либо с помощью знака. Сэмейон, по разъяснению Секста Эмпирика, - знак, а также признак, доказательство - истинный первый член законного условного предложения, который доказывает (выводит) неочевидный второй член в качестве истинного. Стоик утверждает в сочинении Филодема, что такое условное предложение только тогда имеет доказательную силу, когда связь устанавливается перепроверкой с помощью контрапозиции. Отметим, что таким же образом определяется отношение логического следования и в современных учебниках ${ }^{2}$.

\footnotetext{
${ }^{2}$ «Чтобы установить, является ли рассуждение последовательным, необходимо прочитать его по схеме: "Если А, то В, тогда всегда, если не-В, то не-А". Эта схема имеет следующий чисто логический смысл: "Если из А логически следует В, то из не-В логически следует не-А". . Если отношение логического следования отсутствует при "обратном прочтении", то оно не имеет места и в исходном рассуждении. Данное правило получило в логике название "правила контрапозиции" и является эффективным средством проверки последовательности рассуждений, состоящих из простых или элементарных высказываний... Применяя правило контрапозиции, мы
} 
То есть, как мы видим, стоик предлагает эпикурейцу аналитическую, а не фактическую проверку истинности условного суждения. Предложение «если есть движение, то есть вакуум» только тогда обоснованно, указывает стоик, когда истинна контрапозиция «если нет вакуума, то нет движения». Так называемая аналогия, т.е. частое наблюдение взаимосвязи и отсутствие очевидно подтвержденной противоположности (на чем настаивали эпикурейцы), не достаточна для установления истинности такой импликации. Эпикуреец, который в этом сочинении, не в пример другим эпикурейцам, не только не выражает антипатии к логике, но и разбирается в ней не хуже стоика, возражает на это, что контрапозиция может быть хорошим критерием, но, однако, не единственным. Напротив, истинность такой импликации основана на том, что «невозможно первому члену импликации быть истинным, в то время как второй не истинен». Эпикуреец в этом рассуждении использует определение стоиков, а именно знаменитую таблицу значений Филона, что указывает на то, что спор вокруг импликации существовал не внутри стоической школы, а давно уже вышел за ее пределы. Как же стоическая логика, точнее, александрийская школа диалектики, уточняла понятие импликации?

С точки зрения современной математической логики ценность стоической логики состоит в том, что используемое этой эллинистической школой диалектики определение условной связи точно соответствует тому, что называется материальной импликацией $[1$, т. 1 , с. 172-173]. Но это не единственное стоическое определение импликации, к тому же оно, как известно, идет не от стоиков, а от мегарика Филона, при этом представляет собой лишь одно из часто используемых определений. Секст Эмпирик приводит и другие, предлагает решить вопрос об обязательном определении и при этом не ограничивается учением стоиков. Речь идет больше о мегарике Диодоре Кроносе, учение которого унаследовали стоики. «Филон говорит, что правильная связь -

одновременно определяем, связаны ли посылки и заключение по смыслу и существует ли между ними отношение логического следования. Если мы получаем одновременное выполнение обоих условий, это означает, что рассматриваемое рассуждение является последовательным. Если не выполняется хотя бы одно из условий (связь по смыслу или наличие логического следования), то такое рассуждение будет непоследовательным» [5]. 
та, которая не начинается от истинного, чтобы кончиться ложным, как, например, выражение "если существует день, то я разговариваю", при условии, что будет день и я буду разговаривать; Диодор же считает правильным то, что не могло и не может, начавшись от истинного, кончаться ложным. По его мнению, только что высказанная связь кажется ложной, так как, если существует день, но я замолчал, она началась истинным и кончилась ложным; а следующая связь истинна: “если нет неделимых основных частиц бытия, то существуют неделимые основные частицы бытия", так как, начинаясь от ложного, она будет заканчиваться, по его мнению, истинным. Те же, которые вводят сочетание, считают связь правильной, когда противоположное ее заключение противоречит ее предыдущему. По их мнению, все высказанные связи будут ошибочными, а истинна следующая: “если существует день, то существует день". Судящие же по выразительности говорят, что такая связь правильна, в которой конец, по значению, содержится в предыдущем. По их мнению, "если существует день, то существует день" и всякая удвоенная связь, по всей видимости, будет ложной, так как невозможно, чтобы что-нибудь содержалось в самом себе». [1, т. 2, с. 282]. Из этого отрывка мы можем выделить, по крайней мере, три определения импликации. Определение импликации как состоящей из тождественных высказываний, по мнению Мау, либо вообще не стоическое, либо принадлежит какой-то малой группе стоиков, поскольку согласно всем другим источникам импликация из двух тождественных высказываний допустима. Возможно, этой точки зрения придерживались академики-скептики направления Карнеада. В сочинении же Филодема стоик говорит: «Недопустим "знак" такой формы: так как люди среди нас смертны, то люди везде смертны. Напротив, допустимо следующее: так как люди среди нас - поскольку они люди - смертны, то люди везде смертны». Эта последняя импликация есть «знак» и соответствует вышеприведенному определению, так как благодаря добавлению «поскольку они есть люди» второй член сложного суждения логически содержится в первом.

Ю. Мау считает, что сочинение Филодема убедительно показывает, что оба противника прошли одну и ту же логическую школу - александрийскую школу диалектики. Определение им- 
пликации, которое использовали стоики, не было специфически стоическим, а широко обсуждалось среди других школ. Так, в данном сочинении Филодем защищает эпикурейскую точку зрения наличия пустоты при наличии движения методом аналогии. Эпикуреец говорит, что его способ доказательства по аналогии идентичен в основе стоическому способу контрапозиции, который соответствует третьему определению условной связи. Эпикурейцы основывали свои научные положения на отсутствии положений, противоречащих очевидному. Эпикуреец указывает, что для «знака» недостаточно того, чтобы оба факта в наблюдении вместе повторялись, но необходимо, чтобы присоединялся постоянно факт отсутствия того, что противоречит очевидному. А это, собственно, и предполагает метод контрапозиции. Например, если день, то светло. Противоречащим очевидному мыслилось бы положение, при котором наступил бы день, а светло не стало бы. Только такой случай исключается первым определением импликации. Из этого примера видно, что эпикурейский метод не противоречит стоическому. Их позиции различны, но средства по существу сходны, причем средства именно логические, а не эпистемические. Здесь вновь возникает все тот же вопрос: почему в споре отсутствуют указания на аристотелевскую силлогистику? Обычно это объясняют тем, что метафизические воззрения стоиков противоречили аристотелевским. Но это объяснение не является удовлетворительным, так как уже Теофраст и Эвдем при развитии аристотелевской логики разрабатывали обсуждаемые здесь гипотетические выводы. Причина заключается, возможно, в следующем. Построенная на родовидовых связях аристотелевская силлогистика предназначалась в основном для решения задач естествознания - задач определения и классификации, как это представлено в «Истории животных» Аристотеля. Напротив, расцветшая в александрийское время математика и строго систематизированная этика стоиков нуждались в несколько иных логических средствах, не рассмотренных подробно Аристотелем. По мнению Ю. Мау, логика высказываний была выработана в основном стоиками, потому что именно эта философская школа нуждалась в таком средстве позитивного доказательства. Однако было ли такое средство принципиально новым? Современная логика показала, что система 
Аристотеля и система стоиков не исключают друг друга. Категорическое высказывание в логике предикатов выражается через импликацию. На возможность перевода категорического высказывания в условное указал Гален во «Введении в логику» и на этом основании объединил аристотелевскую и стоическую системы. Во всяком случае, мы видим, что уже в трудах Аристотеля и его учеников была заложена та мощная логическая система, которая предвосхитила позднейшие открытия. Завершая статью, Ю. Мау делает следующие выводы: 1) в античности имелась одна логическая школа, общая для представителей всех философских школ; 2) уже в то время были заложены основания логики, применяющей исчисления; 3) эти положения для исчислений возникли не вне чистой логики, а составляли с ней единство, так же как тогдашние естественные науки не могли быть отделены от натурфилософии.

В заключение своей статьи Ю. Мау выражает сожаление, что не смог проследить продолжение этой традиции в раннем средневековье, прежде всего у Боэция и Марциана Капеллы. Этот труд мы взяли в данной статье по мере сил на себя, привлекая для анализа, прежде всего, трактат Боэция «О гипотетических силлогизмах» $[6]$.

\section{2 Отношение логического следования в трактате Боэция «О гипотетических силлогизмах»}

В трактате Боэция сразу обращает на себя внимание тот факт, что исследование о гипотетических силлогизмах опирается не на работы стоиков, а лишь на труды Аристотеля и его учеников Теофраста и Эвдема, имена которых вместе с однократным упоминанием Цицерона только и встречаются в трактате. Мы знаем, что Аристотель начал исследовать виды сложных суждений $[7]^{3}$, но, видимо, не успел закончить. Эту работу, как уже было сказано, проделали его ученики Теофраст и Эвдем, которым и принадлежит разработка схем гипотетических силлогизмов, часть из которых стоики выбрали в качестве «простых недоказываемых аргументов». Однако эта работа учеников Аристоте-

\footnotetext{
${ }^{3}$ Об условных суждениях см. «Топика» II , 5, 112 а 16-23, об исключающей дизъюнкции - «Топика» II, 6, 112 а 24-31, а также другие рассуждения в «Первой Аналитике».
} 
ля в оригинале не сохранилась. Мы предполагаем, что данный трактат Боэция в большей степени является переложением идей, а возможно, и самого трактата Теофраста и/или Эвдема.

Согласно Боэцию, всякий силлогизм состоит из предложений, которые могут быть либо категорическими (простыми): человек есть животное, либо гипотетическими, условными: если есть день, то есть свет.

Гипотетические предложения состоят из категорических. В речи два предложения человек есть животное, и если есть человек, то есть животное почти не различаются, но различие между ними все же есть. Во-первых, первое высказывание простое, второе - сложное. Во-вторых, в первом субъект принимает имя предиката (человек принимает имя животное), во втором виде предложений выдвигается некоторое условие, например, если родила, то имела соитие с мужем. Здесь не говорится, указывает Боэций, что родить есть то же, что иметь coumuе с мужем, а лишь указывается, что родов не было бы, если бы не было соития с мужем. Значит, термины могут и не принимать имена друг друга. Боэций хочет показать, что форма одного предложения легко преобразуется в форму другого, но это не означает их полного совпадения. Если первое предложение в силлогизме - гипотетическое, то он называется гипотетическим. Но так как всякое гипотетическое предложение состоит из категорических, то гипотетический силлогизм также можно отнести к числу категорических. Таким образом, силлогизм, в том числе гипотетический, представляет собой и связь предложений, и, поскольку всякое предложение состоит из терминов, также и связь терминов. Это важное замечание Боэция, говорящее о том, что принципиального различия между связью предложений и связью терминов нет, и поэтому гипотетические силлогизмы можно свести к категорическим. Гипотетическое предложение, состоящее из простых - либо утвердительных, либо отрицательных, предполагает 4 сочетания: Утвердительные высказывания: 1) если $a$, то $b, 2)$ если не- $a$, mo $b$. Отрицательные высказывания: 3) если $a$, то не-b, 4) если не- $a$, то не-b.

По обычаю «младших» перипатетиков, т.е. стоиков, такие сочетания записываются так: если 1-ое, mо 2-ое, и т.д. Следование, по Боэцию, это связь терминов, которую он понимает не только 
в смысле материальной импликации, но в смысле связи особого рода терминов. Связь следования одного термина из другого носит двоякий характер: либо они связаны привходящим образом, к примеру, если огонь жаркий, то небо круглое, либо последовательность заключена в самой природе. Во втором случае имеются два варианта: 1) связь терминов выражает не причинную связь, а только родовидовую (если человек, то животное). Здесь вид выступает основанием, а род - следствием, хотя на самом деле причина и начало вида есть род; 2) связь терминов, следование носит необходимый причинный характер, к примеру, если Земля заслоняет Луну, то происходит лунное затмение. Далее Боэций рассматривает следование с точки зрения модальной силлогистики, используя определение необходимого и невозможного, данные Аристотелем. Он приходит к выводу, что необходимым следование будет только: 1) если есть первое, то необходимо есть второе, и 2) если второго нет, то необходимо, чтобы не было первого. Связь терминов в гипотетическом силлогизме, таким образом, приобретает не условный, а необходимый характер, а гипотетические силлогизмы становятся не диалектическими, а аподиктическими. Заметим, что в трактате Боэция определение логического следования разъясняется через контрапозицию терминов.

Из дальнейшего анализа Боэция мы видим, что определение логического следования через контрапозицию он относит к Аристотелю. Оно неоднократно и в явной форме дано Аристотелем в так называемом доказательстве через невозможное (impossibilitas).

Следование если есть $a$, то есть $b$ имеет место, когда, признав $a$, необходимо признать $b$. То, что $a$ необходимо влечет $b$, доказывается через невозможное: если будет а, необходимо быть b, поэтому, если не будет $b$, не будет и а. Предположим, что b нет, но при этом есть, если такое возможно, а. Но сказано, что если есть а, необходимо признать $b$. Следовательно, мы установили, что $b$ и будет и не будет одновременно, что невозможно. Невозможно, значит, не быть $b$ и при этом быть $а$ [6].

Эта трактовка следования принадлежит Аристотелю, как и проверка следования при помощи контрапозиции. Не совсем понятно, почему приписывают такое понимание следования ме- 
гарикам, а позже стоикам. Приведем пример из «Топики», где Аристотель объясняет следование через контрапозицию. «Например, если человек - живое существо, тогда то, что не живое существо, не есть человек. И точно так же и в других случаях. Действительно, здесь следование обратное. Ибо из бытия человеком следует бытие живым существом, но из небытия человеком не следует небытие живым существом, а, наоборот, из небытия живым существом следует небытие человеком. Итак, во всех такого рода случаях надо это считать правильным. Например, если красивое приятно, то неприятное некрасиво. Если же последнее не (правильно), то и первое не (правильно). И точно так же если неприятное некрасиво, то красивое приятно» [7, с. 386-387]. Из этого отрывка Аристотеля мы можем сделать еще один вывод: если категорическое высказывание можно свести к условному, то операции противопоставления предиката, используемой Аристотелем, будет соответствовать контрапозиция условного высказывания.

Далее Боэций переходит к вопросу о том, как отрицается условное предложение. Такому предложению противопоставляется то, которое отрицает его сущность. Сущность же этих предложений в том, чтобы сохранить необходимость следования. Если кто прямо опровергает условное предложение, то сделает так, чтобы разрушить следование одного из другого. Ecли есть a, то есть $b$ опровергается тем, что показывается, что после того, как установлено $a$, не следует сразу $b$, и, может быть, термина $b$ и вовсе нет. То есть термин $b$ не необходим, а возможен. Значит, условное предложение отрицается таким образом: если есть $а$, mо нет $b$.

Здесь отменим следующее: Боэций считает, что отрицанием $(a \rightarrow b)$ должно быть не $\sim(a \rightarrow b)$, как мы ожидаем, но $(a \rightarrow \sim$ $b)$. И это можно объяснить так: из отрицания следования $(a \rightarrow b)$ следует отрицание консеквента $\sim b: \sim(a \rightarrow b) \rightarrow(a \rightarrow \sim b)$.

Как и Теофраст, Боэций рассматривает сложные суждения не только как связь предложений, но и как связь терминов, из которых составлены сложные суждения. То есть категорическое суждение представлено как условное:

1. $a \rightarrow b$ : если есть человек, то есть животное;

2. $\sim a \rightarrow b$ : если нет дня, то ночь; 
3. $a \rightarrow \sim b$ : если есть черное, то нет белого;

4. $\sim a \rightarrow \sim b$ : если нет животного, то нет человека.

Отрицанием 1) будет 3), так как надо отрицать сущность термина. Термин Боэций использует в форме предиката, со связкой есть, и отмечает, что условное предложение 2) имеет место только для противоречащих терминов (есть день, есть ночь). Заметим, что для 1) и 4) приведен пример отношения подчинения между терминами (человек, животное).

Далее исследуются гипотетические силлогизмы, состоящие из двух терминов, из трех терминов и из четырех терминов. Выстраивая из указанных нами посылок, состоящих из двух терминов, схемы известных нам как modus ponens (MP) и modus tollens (MT) силлогизмов (их получается 8), Боэций добавляет для посылки $\sim a \rightarrow b$ два «неправильных» модуса (всего получается 10 модусов):

1. $\sim a \rightarrow b, b \vdash \sim a$

2. $\sim a \rightarrow b, a \vdash \sim b$

Как же он объясняет это следование? Дело в том, что данная посылка характеризует отношение между противоречащими терминами, и поэтому силлогизм проходит:

1. Если не денъ, то ночь. Ночь, следовательно, не день.

2. Если не день, то ночь. День, следовательно, не ночь.

Дальше Боэций переходит к силлогизмам, посылки которых состоят из двух гипотетических предложений, и соответственно из четырех терминов: $(a \rightarrow b) \rightarrow(c \rightarrow d)$.

Учитывая, что каждый их четырех терминов может отрицаться, Боэций составляет 40 (из них 8 «неправильных») модусов. Сочетаются посылки сначала по схеме модуса ponens, потом модуса tollens. То есть предложение $(a \rightarrow b) \rightarrow(c \rightarrow d)$ имеет ту же структуру, что и $(a \rightarrow b)$. И точно так же как в силлогизмах с посылкой $(a \rightarrow b)$, образуются 8 «неправильных» модусов, к примеру:

1. $(a \rightarrow \sim b) \rightarrow(c \rightarrow d),(a \rightarrow b) \vdash(c \rightarrow \sim d)$

2. $(a \rightarrow \sim b) \rightarrow(c \rightarrow d),(c \rightarrow d) \vdash(a \rightarrow \sim b)$ 
В них «не природа связи, а свойства терминов (terminorum proprietas) создают следование». Аналогичные модусы возникают из гипотетических посылок, состоящих из трех терминов: $a \rightarrow(b \rightarrow c)$ и $(a \rightarrow b) \rightarrow c$. Здесь Боэций образует из посылки $a \rightarrow(b \rightarrow c) 20$ (из них 4 «неправильных») модусов, из посылки $(a \rightarrow b) \rightarrow c$ также $20(16+4)$ модусов. Таким образом, добавляется еще 8 «неправильных» модусов, аналогичных модусам (1) и (2), например:

1. $\sim a \rightarrow(b \rightarrow c), a \vdash b \rightarrow \sim c$

2. $(a \rightarrow \sim b) \rightarrow c, a \vdash b \rightarrow \sim c$

Боэций так объясняет появление этих модусов: «Здесь потому есть вывод на той и другой стороне, что эти предложения могут излагаться в терминах непосредственно противоположных (immediata contraria), так как в них утверждение одного термина отрицает другой, а отрицание одного утверждает другой» $[6$, c. 298].

Далее он переходит к посылкам, состоящим из двух гипотетических предложений, но из трех терминов, т.е. имеющих один общий термин. Состоящие из трех терминов Боэций распределяет по трем фигурам, каждая из которых имеет как правильные, так и неправильные модусы.

Изобразим три фигуры гипотетических силлогизмов Боэция (как они даны им в тексте без заключений), отличающиеся как от фигур Теофраста, так и от фигур Филопона и Александра Афродизийского:

$$
\begin{aligned}
& \text { I фигура II фигура III фигура } \\
& A \rightarrow B \quad A \rightarrow B \quad B \rightarrow A \\
& B \rightarrow C \quad \text { не- } A \rightarrow C \quad C \rightarrow \text { не- } A \\
& \text { Схемы Теофраста }
\end{aligned}
$$

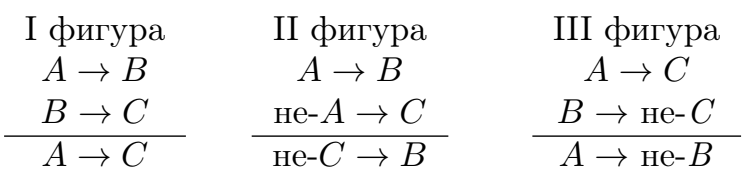


Схемы Александра Афродизийского

$$
\begin{aligned}
& \text { I фигура II фигура } \quad \text { III фигура } \\
& A \rightarrow B \quad A \rightarrow B \quad A \rightarrow B \\
& \begin{array}{ll}
B \rightarrow C & \frac{C \rightarrow \text { не- } B}{A \rightarrow \text { не- } C} \quad \text { не- } A \rightarrow C \\
B \rightarrow C
\end{array} \\
& \text { Схемы Филопона }
\end{aligned}
$$

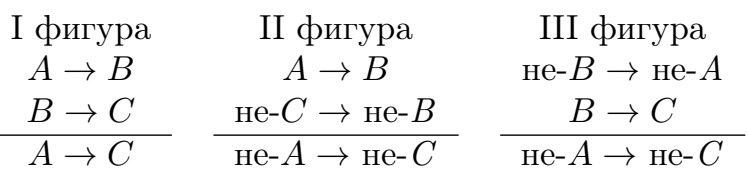

У Боэция по каждой фигуре образуются 8 модусов, контрапозицией заключения добавляются еще 8 модусов (итого по трем фигурам 48 модусов), среди которых «неправильных» нет. Приведем пример по второму модусу первой фигуры:

$a \rightarrow b, b \rightarrow \sim c \vdash a \rightarrow \sim c:$ если человек, то животное, если животное, то не камень. Значит, если человек, то не камень.

Всего модусов с соединительными посылками насчитывается $10+10+40+20+20+48=148$, которые методично, с содержательными примерами выписываются Боэцием. Из них 20 «неправильных». После этого Боэций переходит к гипотетическим силлогизмам с разделительными посылками. Их, как и условных посылок, 4 вида:

1. а либо b: либо болен, либо здоров,

2. а либо $b$ : либо нет человека, либо есть животное,

3. а либо $\sim b$ : либо есть животное, либо нет человека,

4. $\sim a$ либо $\sim b:$ либо не белое, либо не черное.

По мнению Боэция, эти посылки сходны с соединительными и должны иметь столько же модусов, сколько имели те. Разделительные силлогизмы из первой посылки -- это известные нам modus ponendo tollens (MPT) и modus tollendo ponens (MTP):

1. $а$ либо $b, a \vdash \sim b$

2. $а$ либо $b, \sim a \vdash b$ 
3. $а$ либо $b, b \vdash \sim a$

4. а либо $b, \sim b \vdash a$

Поскольку Боэций, как Аристотель и Теофраст, понимает дизъюнкцию только как строгую (что опять-таки связано со свойствами терминов), все модусы с разделительными суждениями без привычных нам ограничений оказываются выполнимыми.

Закономерно возникает вопрос: почему посылками силлогизмов выступают только условные и разделительные суждения, но не суждения с союзом «и». Почему нет известных нам правил удаления и введения конъюнкции. Конъюнкция не выступает посылкой силлогизма по той причине, что между терминами соединительного суждения нет четкого логического отношения: ни взаимного исключения, ни необходимого следования.

Итак, какие выводы можно сделать из данного трактата Боэция? Теория гипотетических силлогизмов намечалась в трудах Аристотеля, но не была им построена. Она была развита Теофрастом и Эвдемом в несохранившихся трудах. О стоиках и их логической системе не упоминается. Как и у стоиков, отношение логического следования определяется через контрапозицию. Идею объяснения следования через контрапозицию Боэций относит к аристотелевскому доказательству через невозможное, которое, в свою очередь, вытекает из аристотелевских категорий возможного и необходимого. Но при этом говорится не о следовании одного предложения из другого, а о следовании одного термина из другого. В отличие от стоиков Боэций не считает связь предложений иной, чем связь терминов. Классификация силлогизмов производится по числу терминов. Те, что начинаются с условной посылки, делятся на два типа: МП и МТ. Изза свойств терминов добавляются два «неправильных» модуса. Далее, независимо от числа терминов (2, 3 или 4), силлогизмы строятся либо по схеме МП, либо по схеме МТ с добавлением аналогичных «неправильных модусов». Итого получается 148 модусов с условными посылками. Часть из них получена путем контрапозиции заключений, как у Аристотеля в категорических силлогизмах. Таким образом, операции противопоставления предикату категорического высказывания ставится в соответствие контрапозиция условного. 
Далее добавляются силлогизмы с разделительными посылками и выводятся модусы МРТ и МТР. Эти 4 модуса (МР и MT, МРТ и МТР) и составляют систему гипотетических силлогизмов Теофраста. Собственно, эти модусы мы уже отметили у Аристотеля. У стоиков к этим 4 гипотетическим силлогизмам добавлен так называемый модус Хризиппа, с отрицанием конъюнкции. То, что среди рассмотренных Боэцием схем нет этого третьего в списке стоиков модуса, указывает на то, что Боэций пользовался при написании трактата только работами Теофраста и Эвдема (о чем сам и говорит), но не работами стоиков. Что касается вклада Боэция, этот вопрос трудно решить, так как трактаты Теофраста утеряны. Но мы можем сделать предположение, что, как и в случае с трактатами Аристотеля, Боэций глубоко изучил материал, сам классифицировал модусы и, возможно, вывел свои. Главный вопрос: кто добавил «неправильные» модусы, сопроводив их учением о свойствах терминов? По крайней мере, у Аристотеля мы не нашли таких положений. Хотя есть замечания, что разделительные суждения предполагают взаимоисключающие термины. Не исключено, что это может быть добавление Боэция. Так же как и обращение частноотрицательных суждений.

Таким образом, Боэций трактует логическое следование не как материальную импликацию, а как связь терминов, которая к тому же согласуется со свойствами этих терминов.

\section{3 Отношение логического следования в трактатах Боэция «Комментарии на "Топику" Цицерона" и «О топических различиях». Анализ Боэцием «недоказуемых» стоиков}

Теорию гипотетических силлогизмов Боэций развивает также в трактатах «Комментарии к "Топике" Цицерона» и «О топических различиях». Проблемам, анализируемым в этих трактатах, посвящены опубликованные нами статьи $[8,9]$, а в данной статье мы рассмотрим только одну проблему, связанную с «неправильными» модусами в анализируемой Боэцием стоической аксиоматике. Отметим, что эти два трактата, в отличие от разобранного выше, написаны позже и базируются на работах стоиков, а не перипатетиков. Несмотря на это, Боэций по-прежнему трактует 
логическое следование как связь терминов. «Топика» Цицерона, написанная в I в. до н. э., является, по-видимому, самым ранним источником, в котором излагаются схемы «недоказуемых» стоиков, при этом список включает не 5 , а 7 силлогизмов: «K ним (пяти. - Л.Т.) добавляют отрицание соединения: "Ложно, что первое и второе; но первое, следовательно, не второе"». Это шестой способ. Седьмой: «Ложно, что и первое, и второе; но не первое, следовательно, второе» [10, с. 68-69].

Здесь к тексту Цицерона сделано следующее примечание издателей: «Шестой и седьмой способы не имеют логического смысла. Не ясно, ошибка ли это Цицерона или позднейших рукописей» $[10$, с. 488$]$.

Предположение о том, что Цицерон мог ошибиться в описании последнего модуса, маловероятно, так как этот список повторяется с небольшими изменениями у греческих и латинских авторов, как находящихся под влиянием Цицерона, так и ссылающихся на других авторов. Так, Кассиодор указывает в качестве источника труды Мария Викторина, Туллия Марцелла и даже Варрона. Исследователь логики Стои М. Фреде [11] предполагает, что у Хрисиппа было 5 схем, а его последователи, поздние стоики, добавили новые. В связи со сказанным может вызвать интерес то место Комментариев Боэция к «Топике» Цицерона, где он анализирует 7 «недоказуемых». Интерес этот подогревается еще и тем, что в своем основном труде по этой теме, в трактате «О гипотетических силлогизмах», Боэций вовсе не приводит этот список. Позднее, комментируя «Топику» Цицерона, Боэций располагал уже другими, стоическими источниками. При этом он все же замечает, что все об условных силлогизмам он уже изложил в книгах «О гипотетических силлогизмах», теперь же прибавляет лишь то, что могло бы истолковать мысли Цицерона. Как в «Комментариях на "Топику" Цицерона», так и в трактате «О топических различиях» Боэций излагает учение стоиков о 7 «недоказуемых»: «Следовательно, из тех предложений, которые связаны, получится первый и второй модусы гипотетического силлогизма, если же прибавляется отрицание в связанное предложение, состоящее из двух утвердительных, и, сверх того, отрицается само предложение, то это дает третий модус; из дизъюнктивных предложений различным 
способом прибавленное дает четвертый и пятый модусы, а тот, и другой, выраженные через отрицание - шестой и седьмой» $[12,1135 \mathrm{~B}-1137 \mathrm{~A}]$.

Для лучшего понимания всего отрывка изобразим модусы в символической форме и приведем примеры Боэция к ним:

I. $1 \rightarrow 2,1 \vdash 2$ : если день, то светло, при этом день, светло;

II. $1 \rightarrow 2, \sim 2 \vdash \sim 1:$ если есть день, то светло; при этом не светло, значит, нет дня;

III. $\sim(1 \rightarrow \sim 2), 1 \vdash 2$ : неверно, что если есть денъ, нет света, но день есть, значит, есть свет;

IV. (1్2), $1 \vdash \sim 2:$ либо день, либо ночь, но день, значит, не ночь;

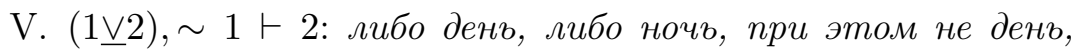
значит, ночь;

VI. $\sim(1 \& 2), 1 \vdash \sim 2:$ неверно, что и денъ и ночь, при этом день, значит, не ночв;

VII. $\sim(1 \& 2), \sim 1 \vdash 2$ : неверно, что и день и ночь, при этом не день, значит, ночь.

Для первого модуса Боэций приводит и другой пример: если человек, то смеющееся существо; при этом человек, значит, смеющееся; а также: при этом смеющееся, значит, человек. Причина обратного следования в том, что человек и смеющееся - равные термины.

В третьем модусе Боэций видит двойное отрицание консеквенции, которое дает утверждение. При этом Боэций замечает, что Цицерон привел два примера из четырех возможных: предложения, состоящего из двух отрицательных, и предложения, состоящего из утверждения и отрицания. Боэций добавляет еще два и примеры ко всем.

IIIа. $\sim(1 \rightarrow 2), 1 \vdash \sim 2$ : неверно, что если бодрствует, то спит, при этом бодрствует, значит, не спит. 
IIIb. $\sim(\sim 1 \rightarrow \sim 2), \sim 1 \vdash 2$ : неверно, что если нет дня, нет ночи, при этом дня нет, значит, ночь.

IIIc. $\sim(\sim 1 \rightarrow 2), 1 \vdash 2:$ неверно, что если нет дня, есть свет, при этом есть день, значит, есть свет.

Шестой модус и седьмой выводятся из четвертой и пятой дизъюнктивных посылок, но, естественно, после того, как дизъюнкция заменяется соединительной связкой и присоединяется отрицание. Шестой и седьмой модусы могут проходить только в тех предложениях, в которых необходимо имеется другое, как день или ночь, больной или здоровый, а чего-либо среднего между ними нет [12, 1133А-1135В].

Из этого отрывка видно, что Боэций располагает стоическим источником, и гораздо увереннее, чем Цицерон или Секст Эмпирик, справляется с логической операцией отрицания. У Цицерона, например, в тексте нет упоминания о снятии двойного отрицания. Можно подивиться тому, с какой методической дотошностью разбирает Боэций каждый случай, нередко при этом повторяясь, однако для нас, историков логики, это обстоятельство оборачивается хорошей стороной - мы через многие столетия имеем точное изложение логических взглядов античных авторов.

Отметим сразу, что в отличие от списка Цицерона, шестой модус не повторяет третий. Все схемы, кроме первых двух, имеют в виду взаимоисключающие термины и предложения. Поэтому и седьмой модус, как указывает Боэций, проходит, хотя, как мы уже говорили, его логическая форма не является общезначимой. Правильность такого рода модусов Боэций в своем трактате «О гипотетических силлогизмах» обосновывает, предлагая учение о свойствах терминов. А именно, если термины взаимоисключающие и между ними нет третьего термина, то добавляется целый ряд модусов, которые можно считать правильными. Впрочем, и в наши дни, мы излагаем модусы условно-категорических силлогизмов ponendo tollens и tollendo ponens с известными оговорками. Примечательно, что Боэций нигде не говорит о нестрогой дизъюнкции. Это не совсем понятно, ибо ему должна была быть 
известна так называемая нестрогая дизъюнкция, которую грамматики стали исследовать, начиная со II в. ${ }^{4}$

Вплоть до наших дней дизъюнкция воспринимается в первую очередь как строгая. Но дизъюнкция - это не просто деление, а различные способы противопоставления. Если мы соотнесем понятие дизъюнкции с отношениями в логическом квадрате, то получим:

- $p \underline{\bigvee q}$ : контрадикторность;

- (p\&q): контрарность;

- $p \vee q ; \sim(\sim p \& \sim q)$ : субконтрарность.

То, что мы называем нестрогой дизъюнкцией, издавна существует в логике под названием субдизъюнкции. При этом различали две формы субдизъюнкции: 1) когда члены субдизъюнкции не могут быть одновременно истинными, но, возможно, могут быть одновременно ложными, 2) когда могут быть одновременно истинными, но не могут быть вместе ложными. Пример Авла Геллия соответствует субдизъюнкции I: в высказывании «либо ты бежишь, либо прогуливаешься. . . » члены дизъюнкции должны взаимно исключать друг друга, в то время как их отрицания могут быть вместе истинными.

- $1 \underline{\vee} 2$ : дизъюнкция;

- (1\&2): субдизъюнкция I;

- $1 \vee 2 ; \sim(\sim 1 \& \sim 2)$ : субдизъюнкция II.

Как видим, термин «субдизъюнкция» введен достаточно корректно: дизъюнкция есть конъюнкция двух субдизъюнкций - I и II: $1 \underline{\vee} 2 \leftrightarrow \sim(1 \& 2) \& \sim(\sim 1 \& \sim 2)$.

Если соотнести виды субдизъюнкций с видами противопоставлений, то увидим, что субдизъюнкция I соответствует контрарности, а субдизъюнкция II - субконтрарности (см. выше).

\footnotetext{
${ }^{4}$ Впервые грамматический союз, соответствующий неисключающей дизъюнкции, употреблен в Дигестах - римском сборнике юридических текстов II в.
} 
Теперь мы можем выдвинуть следующую версию добавления стоиками 6 и 7 модусов гипотетического силлогизма: посылка 7 модуса подразумевала субдизъюнкцию II $[1 \vee 2 ; \sim(\sim 1 \& \sim 2)]$, т. е., в современном понимании нестрогую дизъюнкцию, которая в 4 и 5 модусах не могла быть учтена. А субдизъюнкция I нашла выражение в 3 модусе, для которого Хрисипп приводил следующий пример: «неверно, что некто родился при восходе Сириуса и умрет в море, при этом он родился при восходе Сириуса, значит, он не умрет в море». Высказывания «родиться при восходе Сириуса» и «умереть в море» не могут быть вместе истинными, но могут быть вместе ложными, т.е., несомненно, был такой человек, который не родился при восходе Сириуса и не умер в море. И тогда, говоря о таком человеке: «неверно, что он родился при восходе Сириуса и умер в море» - мы будем иметь истинное высказывание. Таким образом, в 3, и, возможно, в 6 модусах действительно подразумевается антиконъюнкция, она же субдизъюнкция I. Но 7 модус подразумевает, по-видимому, нестрогую дизъюнкцию, т.е. субдизъюнкцию II.

Наша версия оказалась в некотором отношении сходной с версией, представленной в книге известных историков логики В. и М. Нилов. Они предложили следующую реконструкцию семи модусов [13, с. 180]:

1. Если первое, то второе, но первое; значит, второе.

2. Если первое, то второе, но не второе; значит, не первое.

3. Не вместе первое и не второе, не первое; поэтому второе.

4. Либо первое, либо второе, но первое; значит, не второе.

5. Либо первое, либо второе, но не первое; значит, второе

6. Не вместе первое и второе, но первое; значит, не второе.

7. Не вместе не первое и не второе, но не первое; значит, втоpoe.

Как видим, авторы полагают, что посылка 7 модуса подразумевает нестрогую дизъюнкцию, т.е. указанную нами субдизъюнкцию II, но объясняют это тем, что переписчики пропустили 
два отрицания, когда копировали эти модусы. С таким объяснением трудно согласиться, во-первых, потому, что среди источников есть независимые друг от друга, а во-вторых, оно слишком уж внелогическое.

Логическим объяснением перечисленных нами «неправильных» модусов является сложность формализации отношения логического следования.

Проведенный анализ трактатов Боэция позволяет сделать вывод о том, что логическое следование связывает в равной степени и термины и предложения. Именно учет свойств терминов (противоположных, противоречащих либо подчиненных) объясняет введение «неправильных», необщезначимых модусов силлогизмов. Ведь между терминами существуют те же отношения, что и между простыми высказываниями в логическом квадрате. А простые высказывания выражаются в виде сложных, условных, неся в себе разнообразие свойств терминов. Боэций не считает, что стоическая и аристотелевская силлогистика имеют принципиальное отличие и предпринимает немало усилий, чтобы доказать обратное - их взаимосвязь.

\section{Литература}

[1] Секст Эмпирик. Против ученых // Секст Эмпирик. Соч. В 2-х т. М., 1976.

[2] Galen. Einfuerung in die Logik. Kritisch-exegetischer Kommentar mit deutscher Uebersetzung von J.Mau. Berlin, 1960.

[3] Jurgen Mau. Stoische Logik. Ihre Stellung gegenueber der Aristotelischen Syllogistik und dem modernem Aussagenkalkuel // Hermes 85, 1957.

[4] Аристотель. Первая Аналитика // Аристотель. Соч. В 4-х т. Т. 2. М., 1978. 29. $45 \mathrm{~b} 19$.

[5] Федоров Б.И. Доказательство и опровержение // Логика / Под ред. Мигунова А.И., Микиртумова И.Б., Федорова Б.И. М., 2010. С. 201-202.

[6] A.M. Severino Boezio De hypotheticis syllogismis. Paideia Editrice Brescia, 1969.

[7] Аристотель. Топика // Соч. В 4-х т. Т. 2. М., 1978.

[8] Тоноян Л.Г. Учение о гипотетических силлогизмах в Комментарии Боэция к «Топике» Цицерона // Логико-философские штудии - 3 / Под ред. Слинина Я.А., Лисанюк Е.Н. Санкт-Петербургское философское общество, СанктПетербург, 2005. С. 98-116.

[9] Тоноян Л.Г. Была ли ошибка в «Топике» Цицерона? // Вестник СанктПетербургского университета. 2004. Сер.6. Вып. 3. С. 62-67.

[10] Цицерон. Топика. Перевод А.Е.Кузнецова // Цицерон. Эстетика. Трактаты. Письма. М. 1994. С. 56-81.

[11] Frede M. Die Stoische Logik. Goettingen, 1974. S. 157-167.

[12] Stump E. Boethius's In Ciceronis Topica. Cornell University Press, Ithaca and London, 1988

[13] W. Kneale, M. Kneale. The development of logic. Oxford, 1962. 